\title{
DÜBLIN
}

Technological University Dublin ARROW@TU Dublin

2003-01-01

\section{A Wide-band Shorted Planar Monopole with Bevel}

\author{
Max Ammann \\ Technological University Dublin, max.ammann@tudublin.ie \\ Zhi Ning Chen \\ National University of Singapore
}

Follow this and additional works at: https://arrow.tudublin.ie/engscheceart

Part of the Electrical and Computer Engineering Commons

\section{Recommended Citation}

Ammann, M. \& Chen, Z. (2003) A wide-band shorted planar monopole with bevel. IEEE Transactions on Antennas and Propagation, 2003, Vol.51, no. 4, pp.901-903. doi:10.1109/TAP.2003.811061

This Article is brought to you for free and open access by the School of Electrical and Electronic Engineering at ARROW@TU Dublin. It has been accepted for inclusion in Articles by an authorized administrator of ARROW@TU Dublin. For more information, please contact arrow.admin@tudublin.ie, aisling.coyne@tudublin.ie, gerard.connolly@tudublin.ie.

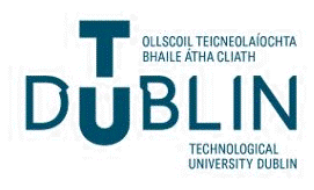




\section{A Wide-Band Shorted Planar Monopole With Bevel}

\author{
M. J. Ammann and Zhi Ning Chen
}

\begin{abstract}
A new wide-band shorted planar monopole with a bevel is presented. The numerical simulations and measurements demonstrate that the impedance bandwidth of a wide-band planar square monopole is shown to increase dramatically by combining bevelling and a shorting technique. The radiation pattern stability is also discussed.
\end{abstract}

Index Terms-Planar monopole antenna, ultra-wideband, wide-band antenna.

\section{INTRODUCTION}

Ultra-wide-band antennas are becoming very attractive for future software defined and reconfigurable wireless systems. The wide-band antenna is simpler than dual-band or triple-band designs of narrow-band elements, which tend to get complicated and may be prone to proximity detuning in some circumstances. Also, some systems may demand more than triple-band operation. Ultra-wide-band (UWB) antennas are an attractive alternative in these cases. Moreover, ultra wideband is an emerging new technology for broad-band internet access and public safety applications, employing the spectrum in the region of 1.9 to $10.6 \mathrm{GHz}$ at extremely low power levels.

The planar monopole antenna was first reported in 1976 by Dubost and Zisler [1] and planar disc antennas have been recently studied [2]. The dependency of the impedance bandwidth on feedgap separation has been analyzed [3] and the method of moments (MoM) employing a wire-grid and finite-gap voltage-feed has been shown to approximate the antenna behavior. Simple formulae have been proposed to determine the lower edge frequency for various planar geometries [3]-[5]. The bandwidth has been increased by adding a shorting post [6] and the use of planar bow-tie geometries have also been examined [4]. The use of parasitic elements has also been investigated [7], [8] and the effect of employing various bevel angles on one or both sides of the feeding probe has been shown to significantly increase the impedance bandwidth [9].

In this paper, the proposed antenna can cover frequencies from 800 $\mathrm{MHz}$ to greater than $10.5 \mathrm{GHz}$. Included in this range of frequencies are GSM, PCS, IMT-2000, DECT, the $2.4 \mathrm{GHz}$, and $5.8 \mathrm{GHz}$ ISM bands, U-NII, and the recent UWB technologies.

\section{SQuare Planar Monopole Antennas}

The simple square planar monopole has been shown to have an impedance bandwidth (2:1 VSWR) of $75-100 \%$ [3] and the addition of a shorting post increases this to about 350\% [5], which represents an impedance bandwidth ratio of $3.5: 1$. However, although an impedance bandwidth ratio of up to $3.5: 1$ is feasible with this element, future systems may demand more, up to $10: 1$. The addition of a bevel on one side of the shorted planar monopole as shown in Fig. 1 increases the bandwidth dramatically. An impedance bandwidth ratio of $10: 1$ for a $3: 1$ VSWR is achievable. Trimming the square edge near the groundplane yielding trapezoidal and pentagonal shapes, has been shown to increase the upper edge frequency significantly [5].

Manuscript received May 20, 2001; revised March 12, 2002.

M. J. Ammann is with the School of Electronic and Communications Engineering, Dublin Institute of Technology, Dublin 8, Ireland.

Z. N. Chen is with the Center for Wireless Communications, National University of Singapore, TeleTech Park, 117674 Singapore.

Digital Object Identifier 10.1109/TAP.2003.811061

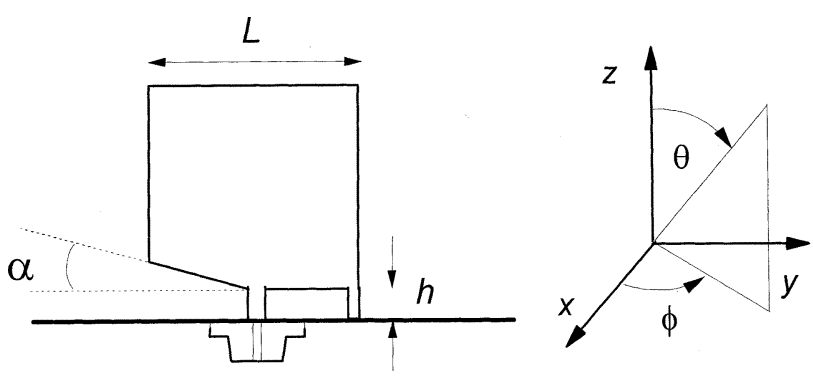

Fig. 1. A square planar monopole with bevel and shorting post is fed using an SMA connector, through a 200-mm square groundplane.

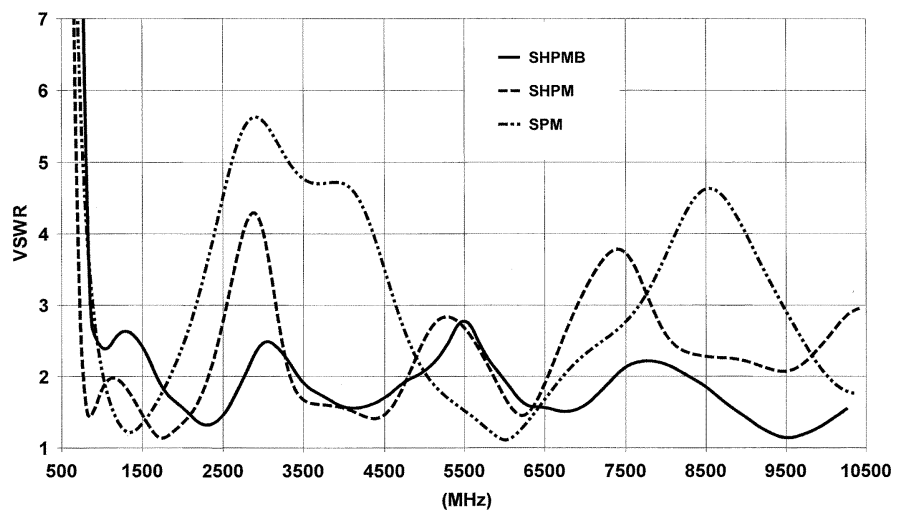

Fig. 2. MoM simulated VSWR for the SPM, SHPM, and SHPMB.

The introduction of a bevel increases the upper-edge frequency, and control of this frequency is possible by adjusting the bevel angle [9]. Increasing the angle of the bevel raises the upper-edge frequency until the bevel angle reaches about $40^{\circ}$. Cutting slots in each side of the planar element also reduce the lower-edge frequency slightly.

The antenna is constructed using 0.2-mm-thick copper sheet on a 200-mm-square groundplane and a SMA connector. The square dimension, $L$, is $60 \mathrm{~mm}$, the shorting strip is $2-\mathrm{mm}$-wide and the feedgap is $1.2 \mathrm{~mm}$. The square geometry is beveled on the side opposite the shorting strip and the bevel angle $\alpha$ was varied from $0^{\circ}$ to $40^{\circ}$ in $10^{\circ}$ steps.

\section{IMPEDANCE AND PATTERN BANDWIDTH}

The variation of VSWR with frequency was simulated by the MoM using a finite-gap voltage-feed and a wire-grid technique with piecewise sinusoidal basis functions. The simulated results are compared to experimental work. The simulated swept VSWR for the square planar monopole with and without shorting strip and bevel is shown in Fig. 2. The shorting strip reduces the lower-edge frequency and the bevel raises the upper-edge frequency significantly. The plot shows the effect of introducing the bevel and shorting strip on the impedance bandwidth. The feedgaps are optimized for maximum bandwidth in each case. Simulated 3:1 VSWR impedance bandwidths are 890-2250 MHz for the simple planar monopole (SPM), 730-2500 $\mathrm{MHz}$ for the shorted planar monopole (SHPM) and $850 \mathrm{MHz}$ to $>10.5$ $\mathrm{GHz}$ for the shorted planar monopole with bevel (SHPMB).

Experimentally, swept VSWR plots $(0.5-10.5 \mathrm{GHz})$ are shown for the simple planar beveled monopole with bevel angles of $\alpha=0^{\circ}$ to $\alpha=40^{\circ}$ in Fig. 3(a). It can be seen that the VSWR variation with frequency is reduced by the addition of the bevel. Fig.3 (b) displays 


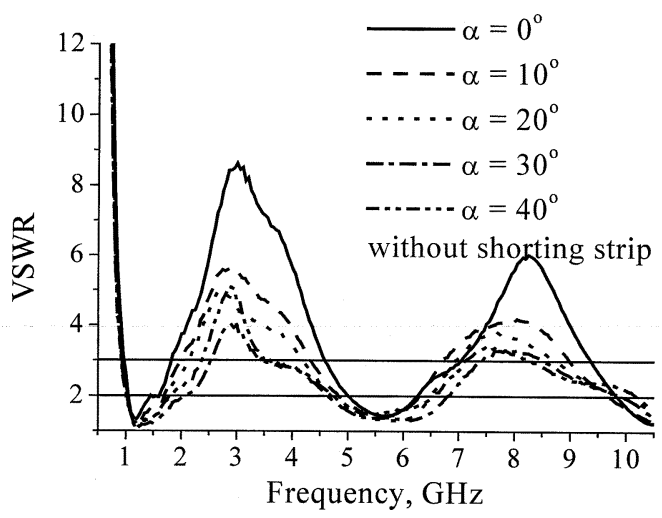

(a)

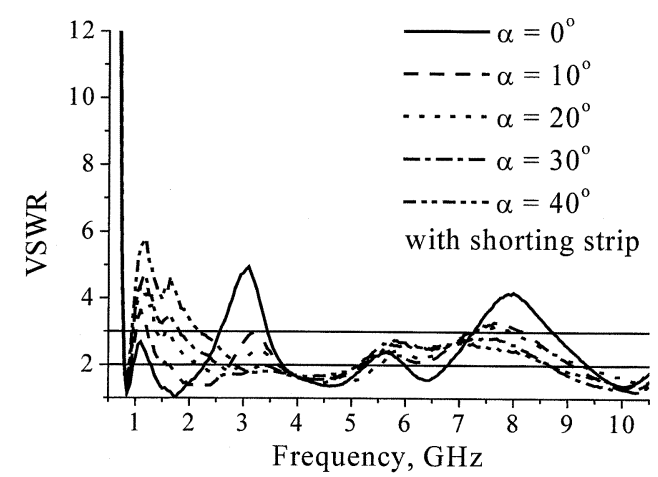

(b)

Fig. 3 (a). Measured VSWR for the 60-mm-square simple planar monopole for $\alpha=0^{\circ}$ to $\alpha=40^{\circ}$. (b) Measured VSWR for the 60-mm-square shorted planar monopole for $\alpha=0^{\circ}$ to $\alpha=40^{\circ}$.

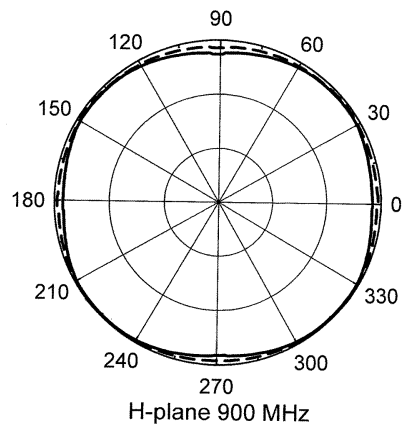

(a)

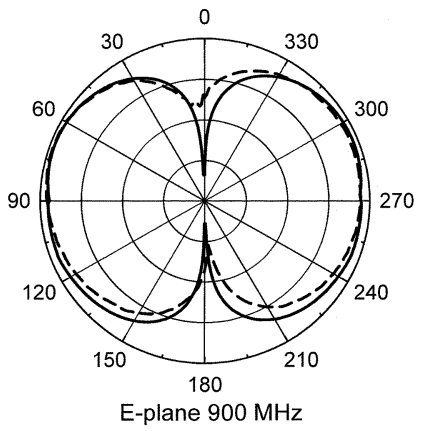

(b)

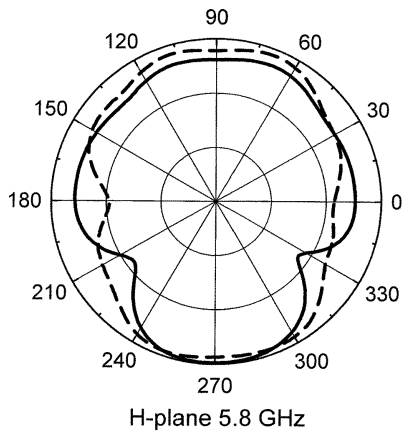

(e)

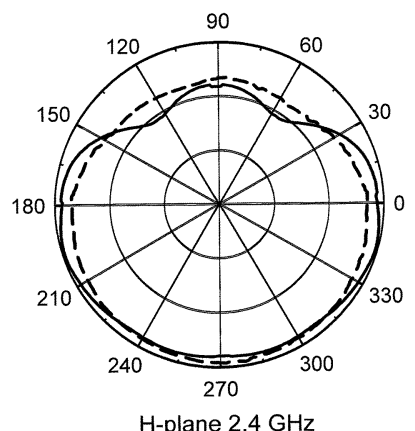

(c)

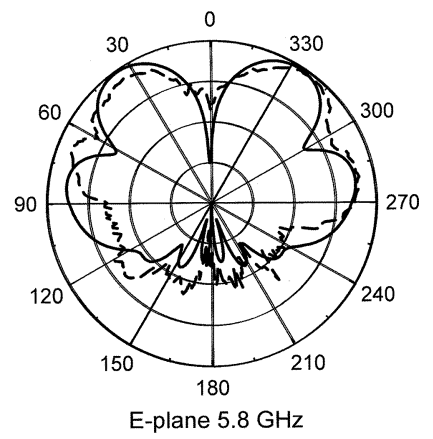

(f)

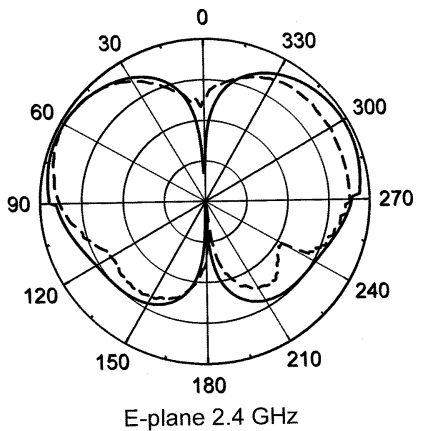

(d)

Fig. 4. The radiation patterns [simulated (solid) and measured (dashed)] of $E_{\theta}$-components in the $\mathrm{H}$ plane $\left(\phi, \theta=0^{\circ}\right)$ and $\mathrm{E}$ plane $\left(\theta, \phi=0^{\circ}\right)$ at $900 \mathrm{MHz}$, 2.4, and $5.8 \mathrm{GHz} .(10 \mathrm{~dB} / \mathrm{div})$.

the VSWR for the planar element with both bevel and shorting strip. It can be observed that the VSWR remains below $3: 1$ over most of the frequency range when $\alpha=10^{\circ}$ and $20^{\circ}$. The bevel tends to increase the VSWR slightly at the lower frequencies but reduces the VSWR significantly at higher frequencies. For $\alpha=10^{\circ}$, the lowerand upper-edge frequencies (3:1 VSWR) are $790 \mathrm{MHz}$ and $>10.5$ $\mathrm{GHz}$, respectively. The VSWR is slightly greater than $3: 1$ only in the regions from $1.05-1.22 \mathrm{GHz}$ and from $7.5-8.2 \mathrm{GHz}$.

The measured radiation patterns shown in Fig. 4 are generally in good agreement with simulated data by MoM combined with the uniform theory of diffraction (UTD). The plots indicate nearly omnidirectional patterns in the $\mathrm{H}$ plane and typical monopole patterns in the $\mathrm{E}$ plane cuts at the lower frequencies. The plots are given at $900 \mathrm{MHz}, 2.4$, and $5.8 \mathrm{GHz}$. The UTD ray paths included singly and doubly reflected fields, singly diffracted fields (normal diffracted and slope diffracted), the reflected-diffracted and diffracted-reflected fields.

\section{CONCLUSION}

A wide-band planar monopole employing two broad-banding techniques has been investigated experimentally and numerically, and is shown to yield an impedance bandwidth ratio of more than $10: 1$ for $\mathrm{VSWR}=3: 1$. The typical monopole radiation patterns have also been seen over the broad bandwidth.

\section{REFERENCES}

[1] G. Dubost and S. Zisler, Antennas a Large Bande. New York: Masson, 1976, pp. $128-129$

[2] P. A. Agrawall, G. Kumar, and K. Ray, "Wideband planar monopole antennas," IEEE Trans. Antennas Propagat., vol. 46, pp. 294-295, Feb. 1998.

[3] M. J. Ammann, "Square planar monopole antennas," in Inst. ELect. Eng. NCAP, York, U.K., 1999, IEE Publication no. 461, pp. 37-40. 
[4] Z. N. Chen, "Impedance characteristics of planar bow-tie-like monopole antennas," Electron. Lett., vol. 36, no. 13, pp. 1100-1101, 2000.

[5] J. A. Evans and M. J. Ammann, "Planar trapezoidal and pentagonal monopoles with impedance bandwidths in excess of 10:1," IEEE AP-S, (Digest), vol. 3, pp. 1558-1561, July 1999.

[6] M. J. Ammann and L. E. Doyle, "Small planar monopole covers multiband BRANs," in Proc. 30th Euro. Microwave Conf., vol. 2, Paris, 2000, pp. 242-246.

[7] Z. N. Chen and M. Y. W. Chia, "Broadband monopole antenna with parasitic planar element," Microw. Opt. Technol. Lett., vol. 27, no. 3, pp. 209-210, 2000.

[8] Z. N. Chen, "Broadband planar monopole antenna," Inst. Elect. Eng. Proc: Microw. Antennas Propagat., vol. 147, no. 6, pp. 526-528, 2000.

[9] M. J. Ammann, "The pentagonal planar monopole for digital mobile terminals: bandwidth considerations and modeling," in Proc. 11 th ICAP, UMIST, vol. 1, 2001, pp. 82-85.

\section{Finite Ground Plane Effects on Broad-Band Dual Polarized Patch Antenna Properties}

\author{
Kin-Lu Wong and Tzung-Wern Chiou
}

\begin{abstract}
Effects of finite ground plane on isolation and radiation properties of a broad-band dual-polarized aperture-coupled patch antenna are experimentally investigated. The dual-polarized patch antenna has a thick air substrate for broad-band operation $(>16 \%$ for both polarizations) and is excited by microstrip lines through two $\mathrm{H}$-shaped coupling slots. Results show that by selecting suitable ground-plane dimensions, isolation between the two feeding ports can be greatly enhanced by about $10 \mathrm{~dB}$, and the cross-polarization level in the $E$ and $H$ planes can also be improved by about 10 and $5 \mathrm{~dB}$, respectively. Also, the impedance bandwidth increases with decreasing ground-plane dimensions.
\end{abstract}

Index Terms-Dual polarization, finite ground plane, patch antenna.

\section{INTRODUCTION}

For practical applications, microstrip patch antennas are with a finite ground plane. Effects of finite ground plane dimensions on the radiation and impedance characteristics of microstrip patch antennas have also been investigated [1]-[5]. However, for finite ground plane effects on isolation and radiation properties of a dual-polarized microstrip patch antenna, related studies are not available in the open literature. Since dual-polarized microstrip patch antennas are very suitable for applications in wireless communications systems that demand frequency reuse or polarization diversity, related information of the finite ground plane effects will be very helpful for antenna engineers in practical designs. In this communication, we present an experimental study of finite ground plane effects on various properties of a broad-band dualpolarized aperture-coupled patch antenna. The isolation between the two feeding ports, cross-polarization level (XPL) in principal planes, impedance bandwidth, and antenna gain as a function of the ground plane dimensions are experimentally investigated.

Manuscript received July 3, 2000; revised January 22, 2002

The authors are with the Department of Electrical Engineering, National Sun Yat-Sen University, Kaohsiung, Taiwan 804, Republic of China.

Digital Object Identifier 10.1109/TAP.2003.811067

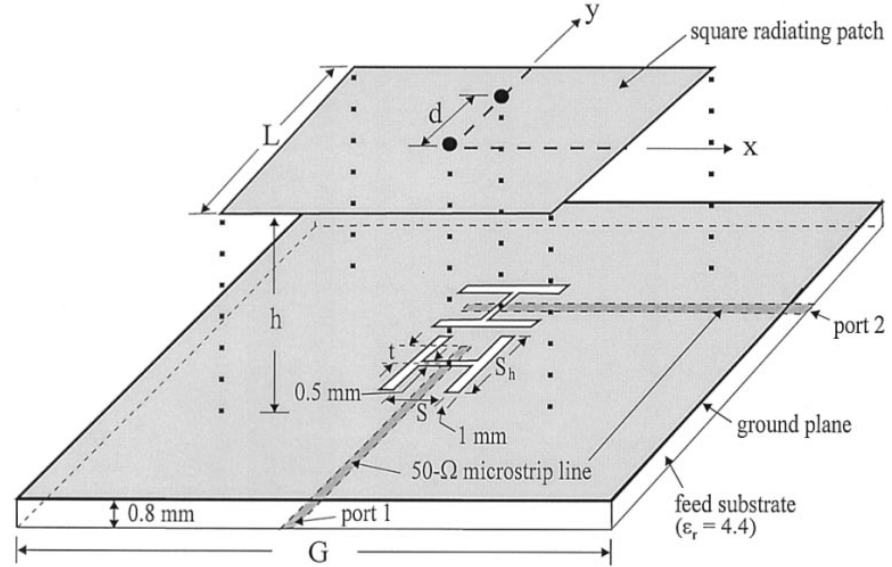

Fig. 1. Geometry of a broad-band dual-polarized aperture-coupled patch antenna with a finite ground plane.

TABLE I

DUAL-POLARIZED PROPERTIES AS A

FunCTION OF GROUND Plane Dimensions; $L=58 \mathrm{~mm}, h=13.6 \mathrm{~mm}$, $d=19 \mathrm{~mm}, S=18 \mathrm{~mm}, t=5.0 \mathrm{~mm}, S_{h}=16 \mathrm{~mm}$. $\lambda_{0}$ IS THE FREE-SPACE WAVELENGTH AT THE DESIGNEd CENTER FREQUENCY $1800 \mathrm{MHz}(f c)$. THE RESUlTS SHOWN ARE FOR PORT-1 EXCITATION. THE IMPEDANCE BANDWIDTH (BW) Is DETERMINED From 10-dB RETURN LOSS. THE ISOLATION GIVEN IS THE MAXIMUM VALUE OF $S_{21}$ ACROSS ENTIRE IMPEDANCE BANDWIDTH

\begin{tabular}{|c|c|c|c|c|c|c|}
\hline \multirow{2}{*}{$\begin{array}{c}L \\
\mathrm{~mm}\end{array}$} & \multirow{2}{*}{$\begin{array}{c}G \\
\mathrm{~mm}\end{array}$} & \multirow[t]{2}{*}{ Impedance BW } & \multirow{2}{*}{$\begin{array}{c}\text { Isolation } \\
\mathrm{dB}\end{array}$} & \multicolumn{2}{|c|}{ XPL at $f_{c}$} & \multirow{2}{*}{$\begin{array}{c}\text { Gain at } f_{c} \\
\quad \mathrm{dBi}\end{array}$} \\
\hline & & & & E-plane & H-plane & \\
\hline \multirow{5}{*}{$\begin{array}{c}58 \\
\left(0.35 \lambda_{0}\right)\end{array}$} & $150\left(0.90 \lambda_{0}\right)$ & $16.7 \%(300 \mathrm{MHz})$ & -35.3 & 32.5 & 19.5 & 7.6 \\
\hline & $100\left(0.60 \lambda_{0}\right)$ & $17.4 \%(314 \mathrm{MHz})$ & -35.5 & 34.3 & 20.0 & 7.1 \\
\hline & $90\left(0.54 \lambda_{0}\right)$ & $18.5 \%(333 \mathrm{MHz})$ & -34.2 & 28.3 & 16.2 & 6.9 \\
\hline & $80\left(0.48 \lambda_{0}\right)$ & $18.7 \%(336 \mathrm{MHz})$ & -29.1 & 25.5 & 15.5 & 6.5 \\
\hline & $75\left(0.45 \lambda_{0}\right)$ & $21.3 \%(384 \mathrm{MHz})$ & -26.0 & 25.0 & 15.4 & 5.5 \\
\hline
\end{tabular}

\section{ANTEnNa Configuration}

Fig. 1 shows the geometry of a broad-band dual-polarized aperturecoupled patch antenna. The antenna's ground plane has dimensions of $G \times G$. The square radiating patch has a side length of $L$. For obtaining broad-band operation, a thick air substrate (thickness $h$ ) was used between the square patch and the ground plane of a grounded substrate (feed substrate; its thickness and relative permittivity in this communication were $0.8 \mathrm{~mm}$ and 4.4 , respectively). Plastic posts (not shown in the figure) were used to support the square patch above the ground plane. Two identical H-shaped coupling slots, whose central arm and two side arms have dimensions of $S \times 0.5 \mathrm{~mm}$ and $S_{h} \times 1 \mathrm{~mm}$, respectively, were used to couple the electromagnetic energy from the $50-\Omega$ microstrip feed lines to the square patch for dual linear polarizations. The microstrip feed lines were printed on the feed substrate and had a tuning stub length of $t$. Also note that the $\mathrm{H}$-shaped coupling slot of port 1 is centered below the square patch (in the $z$-axis), and the central arm of the other $\mathrm{H}$-shaped coupling slot for port 2 is arranged along the direction of the microstrip feed line of port 1 , with the center of the coupling slot having a distance of $d$ away from the central axis ( $z$-axis). This arrangement in the two H-shaped coupling slots can result in optimal isolation between the two feeding ports. In the experiments, the IE3D simulation software was also used for obtaining the initial promising parameters for the communication, and final parameters were determined from experiments. 